This article addresses the relationship between two related behavioral domains in adolescents: sexual activity and mildly deviant behavior (defined as behaviors of which parents would disapprove, but which are not illegal). Previous work has demonstrated overlap between these behavioral domains. We use a unique data set - the data from the Carolina Population Center's Adolescent Sexuality (ADSEX) Project which contain linkable responses of siblings, best friends, and other friends - to quantify the degree of overlap and separation between sexuality and mild deviance. We cast our work in a conceptual context identifying the prominent members of a respondent's environment, including siblings, same-sex friends (best friends and other friends) and opposite-sex friends (best and other friends). Results support previous research showing overlap between sexuality and mild deviance; however, the two domains are also distinguishable. Furthermore, theoretical predictions generated by the conceptual framework-by considering the relationship of adolescents to others in their environment - are supported by the data.

\title{
Adolescent Sexual Activity and Mildly Deviant Behavior
}

\section{Sibling and Friendship Effects*}

\author{
JOSEPH LEE RODGERS \\ University of Oklahoma \\ DAVID C. ROWE \\ University of Arizona
}

\begin{abstract}
There are many costs associated with adolescent sexual activity. Potential biological costs include pregnancy, sexually transmitted disease, and an increased risk of certain types of cancer (e.g., Strobino, 1987). Each of these has concomitant social, economic, psychological, and/or educational costs (e.g., Hofferth, 1987). The potential benefits of adolescent sexual activity are much more immediate, personal, and of less societal scope; they include pleasure, social and interpersonal influence, and affirmation of achieving adulthood.

*The work in this article was supported by National Institute of Child Health and Human Development Grant \#R01-HD21973. The authors thank the reviewers and editors of this special issue for suggestions that improved this article. Reprint requests should be sent to Joseph Lee Rodgers, Department of Psychology, University of Oklahoma, Norman, OK 73019.
\end{abstract}

JOURNAL OF FAMILY ISSUES, Vol. 11 No. 3, September 1990 274-293

(C) 1990 Sage Publications, Inc. 
Within this perspective, it is no surprise that adolescents-whom we might expect to emphasize their own personal and immediate gratification - have become increasingly sexually active (Hayes, 1987; Hofferth, Kahn, \& Baldwin, 1987; Zelnick \& Kantner, 1980), and adults (including researchers and policymakers) - who view adolescent behavior in less personal and more familial or societal terms - have viewed increasing sexuality and pregnancy rates in adolescents as a problem. In the evocative words of Daniel Federman, chair of the recent Panel on Adolescent Pregnancy and Childbearing, "No human experience is at once so transiently private and lastingly public as an unintended pregnancy. ... Many factors beyond the control - even the ken - of the young people involved complicate the scene" (Hayes, 1987, p. xiii). Hayes (1987) states, "Adolescent pregnancy is widely recognized in our society as a complex and serious problem. Regardless of one's political philosophy or moral perspective, the basic facts are disturbing" (p. 1). The Alan Guttmacher Institute (1981) labeled Adolescent Pregnancy "The Problem That Hasn't Gone Away." It is certainly the case that the prerequisite for adolescent pregnancy - adolescent sexual behavior - has also not gone away.

Over the past 15 years, researchers have responded to increasing adolescent sexual activity with increased attention to its causes and consequences. Reviews of the literature on adolescent sexual behavior (e.g., Clayton \& Bokemeier, 1980; Hayes, 1987) often divide this study into two components: epidemiology (incidence) and etiology (causal structures). Researchers within demography, public health, and other policy arenas have emphasized epidemiology; sociologists and psychologists have emphasized etiology.

The current study represents an integrative effort, in which several different lines of research are combined into a single conceptual and analytic framework. Our study is clearly etiological: Our general approach is to consider relationships between siblings and friends within an adolescent's environment as a source of influence on adolescent sexual behavior. Previous work has considered both siblings and friends, but in separate studies. Furthermore, we place adolescent sexual behavior into a broad conceptual domain by comparing adolescent sexual activity to other behaviors that are in some sense "equivalent" (ones that Rodgers, Billy, \& Udry, 1984, termed "mildly deviant behaviors").

We begin with a brief review of the adolescent sexuality literature that motivates the current study. Next, we establish our conceptual and methodological orientation. Following a presentation of our results, we discuss the implications of our study. 


\section{THE ADOLESCENT SEXUALITY LITERATURE}

Clayton and Bokemeier (1980), in their review of the literature from the 1970s, noted two theoretical approaches that had been applied in research on adolescent sexual behavior. First, researchers had built theories to specifically model the phenomenon of interest. Examples include Reiss's (1967) seven propositions defining a theory of sexual permissiveness; Newcomb, Huba, and Bentler's (1986) "domain theory" of adolescent sexuality and dating behavior; and the biosocial models developed by Udry (e.g., Udry, Billy, Morris, Groff, \& Raj, 1985; Udry, Talbert, \& Morris, 1986), establishing that hormones play a major role in developing libido, although social factors seem to have a strong influence on coital activity among adolescent females.

The second type of theoretical effort involves applying previously existing theories to the specific arena of adolescent sexuality. These include applications of reference group theory (e.g., Mirande, 1968), socialization theory (e.g., Spanier, 1976), and attitude-behavior consistency theory (e.g., Clayton, 1972). Of particular interest for the present study is research that has drawn on theories of deviant behavior, considering premarital adolescent coitus to be one of a number of "problem behaviors" in which adolescents engage. Reiss (1970) was among the first to propose this orientation, considering labeling, anomie, and social support systems in relation to adolescent sexual activity and other deviant behaviors. Jessor and Jessor (1977) developed "Problem Behavior Theory," and found that transition to nonvirginity is linked with transition into several other problem behaviors (in particular, drinking and drugs). Others have also shown empirical relationships between adolescent sexual activity and drug use (e.g., Murstein and Holden, 1979; Stern, Northman, \& Van Slyck, 1984; Yamaguchi \& Kandel, 1987; Zabin, Hardy, Smith, \& Hirsh, 1986).

A large body of primarily atheoretic work also exists, in which empirical links are established between adolescent sexual behavior and various other demographic and behavioral correlates. Ensminger (1987) reviewed studies demonstrating relationships between sexual activity and pubertal development, sex, race, socioeconomic status (SES), religion, intelligence, family characteristics, and peer group influence. Apparently, males and females view adolescent sexuality from different perspectives. Studies of college students (McCormick, 1979; Peplau, Rubin, \& Hill, 1977) suggest that females are more inclined to try to avoid sexual intercourse, whereas males encourage it. Furthermore, even in permissive subgroups 
and across cultures, males had more positive attitudes toward casual sexual intimacy than did females (Antonovsky, Shoham, Kavenaki, Lancet, \& Modan, 1980; Carroll, Volk, \& Hyde, 1985; Peplau et al., 1977). There are also major subgroup differences between Blacks and Whites, in that Black teenagers are generally more sexually precocious than Whites (Zelnick, Kantner, \& Ford, 1981). Furstenberg, Morgan, Moore, and Peterson (1987) found support for a socioeconomic explanation of this effect, whereas Rowe, Rodgers, and Meseck-Bushey (1989) attributed at least part of the difference to earlier maturation among Black adolescents.

Reference group theory suggests that parents, friends, classmates, and acquaintances can have effects on an adolescent's behaviors and attitudes. A substantial body of empirical literature supports this assertion. Teevan (1972) found that college students who have close ties to their parents were more sexually conservative than those who do not. Shah and Zelnick (1981), Newcomer and Udry (1987), Stern et al. (1984), and Thornton and Camburn (1987) also found parental influence effects on adolescent sexual activity. Rodgers and Rowe (1988) demonstrated a sibling influence effect, and Billy and Udry (1985) showed that peers can influence sexual behavior (specifically for white females). Jessor and Jessor's (1977) work is concerned with "the role of the environment in youthful problem behavior" (p. 113), including sexual behavior in particular. These and other studies suggest that environmental factors can have both correlational and causal relationships with adolescent sexual behavior.

We take a broad view of what is meant by the environment. Our conceptualization is similar to that of Jessor and Jessor (1977), who considered the environment to be a social-psychological setting in which individuals interact. A family environment is defined in part by the individuals who inhabit it. The variables of interest in the study of such an environment are those that describe the family and its members - both demographic (race, sex, and so on) and behavioral (sexual behavior, attitudes, and so on). The school environment and the friendship environment include different actors than does the family environment (with potential overlap).

Adolescents engage in many behaviors besides those contributing to their sexual experience. A substantial body of recent research attention has been directed toward identifying behaviors that overlap with sexual activity. One type of effort places sexual behavior within an overall social-dating context, as in Newcomb et al.'s (1986) "domain theory." Smith and Udry (1985) considered the typical "path" through such behav- 
iors, and found race differences in the patterns of social and sexual interactions preceding intercourse. Hayes $(1987$, p. 28$)$ places adolescent sexual behavior into a broad framework including contraception, abortion, pregnancy, and childbearing, and considered possible transitions between these various activities.

Of most relevance for the current study is the perspective placing adolescent sexual activity within the framework of "mildly deviant behaviors" (e.g., Rodgers et al., 1984). Jessor and Jessor (1977) defined deviance as a "behavior that is socially defined as a problem, a source of concern, or as undesirable by the norms of conventional society and the institutions of adult authority" (p. 33). Although sexual activity becomes normative with increasing age, for young adolescents it falls within a set of behaviors that most parents would not condone.

One recent theoretical proposal suggests that there is a single "deviance trait" underlying adolescent sexual behavior and other activities like drinking, smoking, cheating, and even some more severely deviant behaviors like robbery, assault, and drug use (e.g., Donovan \& Jessor, 1985; Elliott \& Morse, 1989; Osgood, Johnston, O'Malley, \& Bachman, 1988; Rowe et al., 1989). Osgood et al. (1988) concluded, "theories that treat different deviant behaviors as alternative manifestations of a single general tendency can account for some, but far from all, of the meaningful variance in these behaviors" (p. 81). Rowe et al. (1989) labeled the general underlying deviance trait " $\mathrm{d}$ " (cf. the literature on "g" on the study of intelligence) and found support for the existence of overlap between sexual experience and 12 different measures of deviance in one sample and with 19 measures of deviance in the other. Using a national sample of adolescents, Mott and Haurin (1988) also found overlap between sexual activity, alcohol, and drug use. However, they emphasized that "the large majority of American adolescents are not involved in all of these activities at relatively youthful ages" (p. 136).

Rowe et al. (1988) investigated a very specific theoretical proposition: A single underlying deviance trait would be manifest in significant overlap between measures of sexual behavior and deviance. Given the demonstrated overlap in the Rowe et al. (1988) study, we extend this perspective to include the other side of the question, and attempt to quantify the amount of both shared and unique variance between deviance and sexual experience. We also broaden the etiological consideration of causal factors by comparing the variance in deviance and sexual behavior explained by siblings to that explained by friends. We consider race and sex subgroups separately, given the major differences between them as 
documented above. By using a hierarchical regression procedure, and capitalizing on the breadth of a large adolescent sexuality data set, we develop a comprehensive framework in which to answer these questions.

\section{CONCEPTUAL MOTIVATION AND HYPOTHESES}

Our conceptual framework, focusing on the family environment, suggests that some factors within the environment act to make siblings similar, and other factors act to make siblings different. (Note that genetic influences can affect siblings in these two ways, also, except for identical twins.) These environmental effects can be extended to friends as well; some environmental factors will act to make friends different (e.g., their different families) and some will act to make them similar (e.g., shared experiences in the classroom). The more experiences that friends share, the more likely that they will be similar on behavioral and attitudinal measures.

We cannot, with our data, distinguish genetic from environmental causes among siblings. We can only observe that both factors act to make siblings similar and different, whereas only environmental factors are acting on friends. Thus, when we enter a given child's friends and siblings into competition within a statistical model, we note that the siblings have more latent causes than do the friends.

The data that we use contain information on both best friends and other friends, and on same-sex and opposite-sex friends. Furthermore, we can break sibling pairs into same-sex and opposite-sex pairs. Siblings could be more similar to one another than friends because they share genes and have more "environment" in common. We note, however, that adolescents may spend more time with their friends than with their siblings; both the ability to select friends (which is not available with siblings) and the ability to "age match" suggest ambiguity as to whether we would expect close friends or siblings to be more important "players" in an adolescent's environment.

We do, however, expect best friends to be more similar to one another than to other friends, as suggested by both selection and influence models (e.g., Billy \& Udry, 1985). Furthermore, we expect same-sex siblings and friends to be more similar than opposite-sex friends, for both theoretical and empirical reasons. Theoretically, we expect same-sex siblings and friends to share more activities and influences within the environment. Several empirical studies have documented different same-sex and 
opposite-sex patterns in a cognitive task (Cicirelli, 1976), childhood characteristics (Koch, 1957), and influences on adolescent sexual behavior (Rodgers, 1983).

In addition to sibling and friendship similarity on specific variables measuring sexual experience and deviance, we are also concerned with the "crossover" predictability: That is, how predictable are adolescents' sexual experience measures from their friends' deviance measures, and vice versa? If all the variance between deviance and sexual activity is shared variance (i.e., if the " $\mathrm{d}$ " effect found by Rowe et al., 1988, accounts for virtually all of the variance), then predicting an adolescent's sexual experience from a sibling or friend's sexual experience will not be any different than predicting it from a sibling or friend's deviance. If there is substantial unique as well as common variance (i.e., if the "d" effect found by Rowe et al., 1988, only accounts for some of the variance), then we should be able to predict an adolescent's deviance better from a friend or sibling's deviance than from sexual experience, and vice versa. The " $\mathrm{d}$ " effect found in previous research (e.g., Osgood et al., 1988; Rowe et al., 1989) did not appear to account for the majority of the variance. Thus we predict that there will be separable and identifiable variance accounted for by sexual experience and deviance, and that "within-domain" variance will be a more powerful predictor than "between-domain" variance (e.g., friends' and siblings' sexual experience will predict the respondent's sexual experience better than will their deviance, and vice versa). We note that, because Rowe et al. (1989) used a different subset of the same data that will be employed in the current study, we have a slight empirical advantage in predicting the existence of separate as well as unique variance between sexual experience and deviance. None of our other specific predictions are easily extracted from previous work on the ADSEX data, however.

Our specific predictions are summarized as follows:

1. We expect siblings', best friends', and other friends' behavior to be related to that of the respondents, on both sexual experience and deviance.

2. We expect best friends' behavior to be more related to respondent's behavior than is the behavior of other friends.

3. We expect same-sex siblings' and friends' behavior to be more related to respondent's behavior than is the behavior of opposite-sex siblings and friends.

4. We expect some "crossover" predictability, due to common variance shared between mild deviance and sexuality.

5. However, we expect "within-domain" prediction to be better than "betweendomain" prediction. 


\section{SAMPLE}

The data for this report were collected during the Carolina Population Center's Adolescent Sexuality (ADSEX) Project from 1979 to 1983. A summary of the study will be provided here; Rodgers, Billy, and Udry (1982), among several others, give a more complete account of data collection, nonresponse, and reliability and validity issues. The study used respondents in two different metropolitan areas, Raleigh, North Carolina and Tallahassee, Florida. In Raleigh, 533 students in one junior high school and in Tallahassee, 1,405 students from four different junior high schools responded to survey questions assessing levels of a number of sexual and deviant behaviors. Of the 1,938 respondents, 581 had siblings in the sample, representing 276 different families. For the current analysis, data were available to construct sibling pairs representing 500 children from 250 independent families. Respondents were also linked to up to three male and three female friends, and respondents indicated which of those was a best friend. These studies collected longitudinal data; Round II from Raleigh and Round I from Tallahassee were used, because these rounds contained the most complete friendship and sibling data. The sample yielded 1,711 female best friend pairs and 3,728 other female friend pairs, and 1,705 male best friend pairs and 3,734 other male friend pairs.

\section{DEPENDENT VARIABLES}

The two dependent variables that will be reported in this study are measures of sexual experience and mildly deviant behavior. Each measure is constructed by combining several responses to questions about specific sexual or deviant behaviors. Different forms of each measure were investigated.

Measures of sexual experience have been developed in past research (see Rodgers, Billy, \& Udry, 1982) that use 11 different sexual activities. These range from going on a date to kissing and hugging, mild petting, more intense petting, and intercourse. For each activity, the respondent indicated whether he or she had ever engaged in the activity. Two sexual experience scales were developed. The first counted the number out of the total of 11 behaviors that the respondent had performed (SEXEXCount). The second sorted the activities in terms of increasing intimacy and assigned the value of the most intimate behavior (SEXEX-Scale). Previous research using the ADSEX data suggests a race difference on the 
behavior of these two measures (Smith \& Udry, 1985). For Whites, the measures tend to be virtually identical; for Blacks, they are often different. For our presentation, the Sexual Experience Scale (henceforth, SEXEX) will be used. There were slight differences in the results for the two scales, particularly when considering race differences. The general conclusions were not affected by choice of the scale, however.

In addition to sexual behavior, we are also concerned with "mildly deviant behavior." We define a theoretical distinction between "mildly deviant behaviors" and "severely deviant behaviors." The former includes activities like smoking, drinking, and cheating on tests (see Rodgers et al., 1984). The latter includes activities like drug use and robbery. The major distinction between the two is the fact that the "severely deviant behaviors" are those that are illegal, whereas the "mildly deviant behaviors" are ones of which many parents would disapprove, but which are not illegal. For the total data set, measures of "severely deviant behaviors" were not available in a large enough sample to support sibling analyses (they were not collected in Raleigh, and not until the third round in Tallahassee). Thus this article addresses only "mildly deviant behaviors." Rowe, Rodgers, Meseck-Bushey, and St. John (1989) used the ADSEX and additional data to address the relationship between severe deviance and sexuality within a slightly different framework.

The measure of deviance (DEV) we used was defined by adding up the "yes" responses to the question "Have you ever engaged in ...", for smoking, drinking, and cheating on a test. Thus this measure ranged from 0 to 3. (This measure has been used successfully in several previous studies; see, e.g., Billy, Rodgers, \& Udry, 1984; Rodgers et al., 1984).

A major advantage of this data set is that direct measures of sexual experience and deviance are available for the friends and siblings of these respondents. Previous studies have often had to rely on the respondent's report of their friend or sibling's behavior. Because the ADSEX data came from intact school settings, in which friends and siblings were interviewed, this type of "autistic" correlation can be avoided (see Wilcox \& Udry, 1986, who demonstrated the effect of this autistic component using the ADSEX data).

Two methodological levels are represented in this article. First, we present descriptive results, representing Pearson correlations measuring the similarity between adolescent pairs. Second, we present the results of fitting hierarchical regression models to the data. This permits both control of moderating variables and consideration of sexual and deviant behavior together within the same analytic model. Sibling pairs, best 
TABLE 1

\section{ADSEX General Correlations Between Sexual \\ Experience Scale and Mildly Deviant Behavior Scale for Total Data Set, by Sex and by Sex by Race (sample size in parentheses)}

\begin{tabular}{lll}
\hline \hline Total data set & $r=.30$ & $(1,739)$ \\
Males & $r=.21$ & $(847)$ \\
Females & $r=.39$ & $(892)$ \\
White males & $r=.44$ & $(593)$ \\
Black males & $r=.21$ & $(254)$ \\
White females & $r=.52$ & $(643)$ \\
Black females & $r=.36 \quad(249)$ \\
\hline
\end{tabular}

NOTE: All correlations are significant at $\alpha=.05$.

friend pairs, and other friend pairs define the relationships of interest. Within the analysis, we control for race and sex of partner (sibling and friend).

\section{RESULTS}

\section{DESCRIPTIVE RESULTS}

The descriptive results will be reported in relation to the several questions defined above. First, Table 1 gives the general correlations between sexual experience and deviant behavior. Across the whole data set $(N=1,739)$, the correlation was .30 . Correlations by race-sex categories ranged from .52 for White Females (WF) to .21 for Black Males (BM). These correlations are high enough to support past research suggesting that adolescent sexual activity and mild deviance may overlap as a part of a general deviance "package." However, they are also low enough to suggest that the majority of the variability in one is left unaccounted for by the other. This supports the development of separate but overlapping models for sexual and deviant behavior.

Table 2 reports sibling correlations, separately for sexual experience and deviant behavior. Results are broken down by the sex composition of the sibling pair - male/male, male/female, and female/female. Correlations are notably higher for the female/female pairs than for the other two compositions. Furthermore, female/female sibling pairs were more similar on deviant behavior than on sexual experience, whereas the other two compositions represented approximately equal and lower levels of similarity on both sexual experience and deviant behavior. Because siblings 
TABLE 2

\section{ADSEX Sibling Correlations and \\ Partial Correlations, for Sexual Experience Scale (SEXEX) and Deviant Behavior Scale (DEV) (sample sizes in parentheses are total sibling pairs, both races combined)}

\begin{tabular}{lccc}
\hline \hline Dependent Variable & Male/Male & Male/Female & Female/Female \\
\hline SEXEX & $.25(64)$ & $.18(104)$ & $.41(55)$ \\
SEXEX Age & $.28(63)$ & $.18(104)$ & $.41(55)$ \\
SEXEX Sexual development & $.34(61)$ & $.21(100)$ & $.34(50)$ \\
& & & \\
DEV & $.24(60)$ & $.29(101)$ & $.71(59)$ \\
DEV Age & $.25(60)$ & $.30(101)$ & $.71(59)$ \\
DEV Sexual development & $.27(58)$ & $.30(96)$ & $.67(57)$ \\
\hline
\end{tabular}

NOTE: All correlations are significant at $\alpha=.05$. The second and third row of correlations for each variable are partial correlations, adjusting the relationship for age and sexual development, respectively.

in this sample were usually not the same age, their similarity is potentially attenuated by differences in their ages. For example, a ninth grade student and his seventh grade sibling might be different in their sexual experience at a given point in time (e.g., when the survey information was collected), but similar at the same age. To adjust for this effect, a regression of age on each siblings' score was used to control for the effect of age, and (partial) correlations were computed from the residuals. A variable measuring (self-reported) sexual development was used in a similar manner. Table 2 shows correlations adjusted for age and sexual development. Little effect of this adjustment is observed. We interpret this as suggesting that age was restricted enough in its range in this sample-siblings differed in age by at most two years - that sibling age differences did not affect correlational analyses.

Table 3 reports sibling correlations separately by race subgroups, again broken down by sex composition categories. The female/female similarity appears stronger among Whites for sexual experience and among Blacks for deviant behaviors (although White females are also highly correlated on deviant behaviors). The sex composition categories involving males show only low relationships.

The same set of analyses reported for siblings in Tables 2 and 3 is shown for best friends and other friends in Table 4. In this table, there are separate categories for males and females choosing both same-sex and opposite-sex friends. For sexual experience, female/female friends were similar for both races and male/male friends among Whites. In the White 
TABLE 3

Sibling Correlations, for

Sexual Experience Scale and Deviant Behavior Scale, for Total Sample and for Whites and Blacks Separately (sample sizes in parentheses are total sibling pairs)

\begin{tabular}{llllll}
\hline \hline Dependent Variable & Race Subgroup & Male/Male & Male/Female & Female/Female \\
\hline Sexual Experience Scale & Whites & $.13(33)$ & $-.02(56)$ & $.52(34)^{*}$ \\
& Blacks & $.02(31)$ & $.32(48)^{*}$ & $.20(20)$ \\
& Total & $.25(64)^{*}$ & $.18(104)^{*}$ & $.41(55)^{*}$ \\
& & & & \\
Deviant Behavior Scale & Whites & $.10(32)$ & $.28(56)^{*}$ & $.43(36)^{*}$ \\
& Blacks & $.20(28)$ & $.10(45)$ & $.65(22)^{*}$ \\
& Total & $.24(60)^{*}$ & $.29(101)^{*}$ & $.71(59)^{*}$ \\
\hline
\end{tabular}

*Significant correlation at $\alpha=.05$.

and total data set, best friends were consistently more similar than were other friends. For deviant behaviors, Whites were consistently more similar to their friends than were Blacks, and female/female pairs for both races were more similar than other sex composition categories. For those categories showing substantial similarity, best friends were more similar to one another than to other friends. However, the difference in best friend/other friend similarity appeared lower than for sexual experience.

Comparing Tables 3 and 4 shows that, in most categories, adolescents' sexual experience and deviant behavior correlate at least as highly with their best friends as they do with their siblings (except for Black sisters' deviant behavior). This result supports the interpretation that these similarities have a large environmental component underlying them, and that similarities between adolescent pairs can be caused by both intra- and extra-family processes.

\section{HIERARCHICAL REGRESSION ANALYSES}

In this section, we present results from a set of hierarchical multiple regression (HMR) analyses. The subset of data used in this analysis included those observations for which complete sibling, same-sex, and opposite-sex best friend data were available. Only best friend data were used in this part of the study, because the descriptive relationships were consistently higher for best friends than for other friends (see Table 4). When these rather rigorous data requirements were imposed, the total sample size available for the hierarchical regression analysis was 217 subjects. 


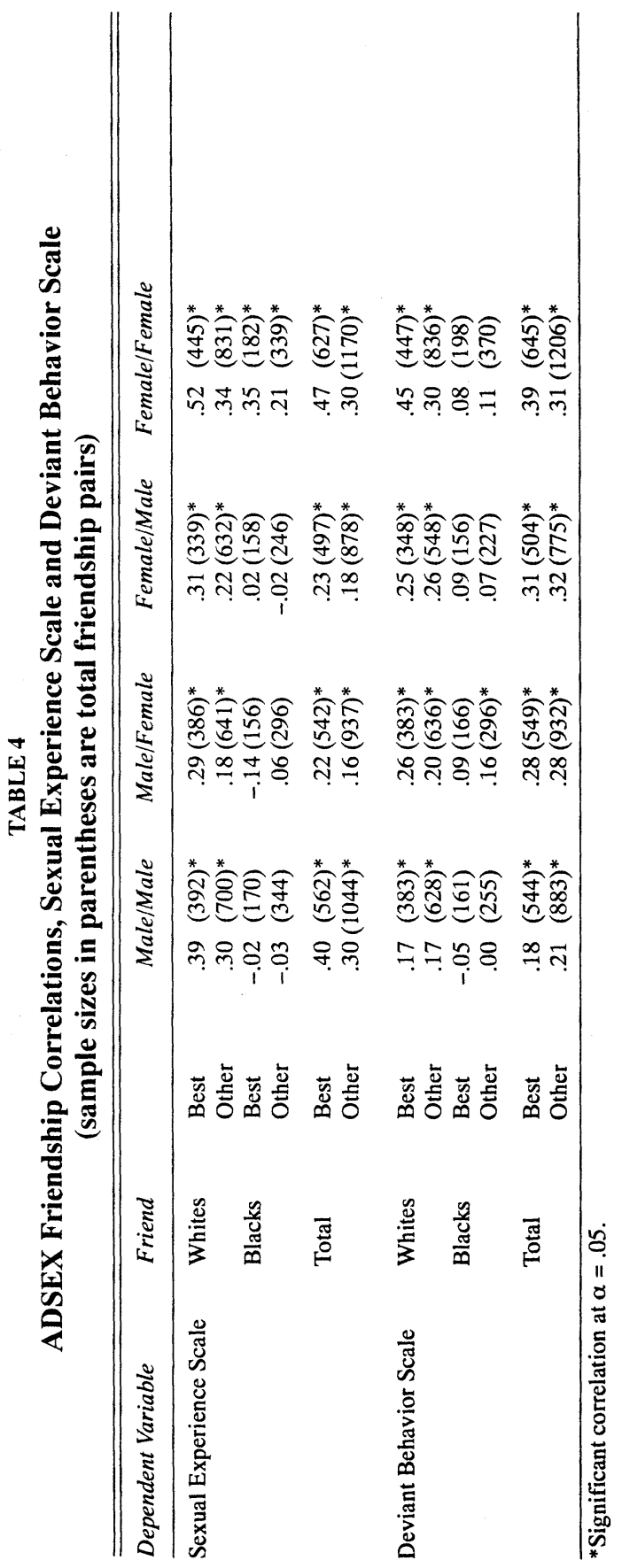


In fact, we will combine features of the hierarchical multiple regression (HMR) procedure and stepwise regression (Cohen \& Cohen, 1975, p. 98 and 102 , respectively). HMR involves entering variables into a set of regression analyses in a specified order. Stepwise regression involves selecting from a subset of variables the subset that most significantly predicts the dependent variable. We will enter variables as "packages" in a specified order. The last "package," however, will be entered stepwise to select the subset of this package that most effectively increases the predictability. This system allows us to fully assess the within- and cross-relationships between a respondent's sexuality and deviance with the sexuality or deviance of siblings and friends.

The dependent variables - sexual experience and deviance - were predicted separately from a set of independent variables (IVs) that were divided into three conceptual "packages." The first included control variables - race and sex of sibling - and were included in every analysis. (Note that sex of friend was also implicitly included within the analysis by including separate scores for best same-sex and best opposite-sex friend.) The second "package" was a set of sexual behavior variables for other persons in the subjects' social environment-siblings, same-sex friends, and opposite-sex friends (whom we will call "relevant others"). The third "package" was the equivalent set of variables for mildly deviant behavior. In each analysis, we were interested in whether relevant other's sexual behavior, deviant behavior, or both would predict a respondent's sexual behavior score; and whether relevant other's sexual behavior, deviant behavior, or both would predict a respondent's deviant behavior. These within-domain and cross-domain relationships were used to quantify the levels of overlap and nonoverlap in the sexual experience and deviance domains. In Table 5, we present the $R^{2} \mathrm{~s}$ for predicting each of the two dependent variables from the three "packages." We note that, in the discussion to follow, all reported $R^{2} \mathrm{~s}$ were statistically significant at $\alpha=.05$ (unless otherwise noted).

The first set of hierarchical regression analyses used respondent's sexual experience (SEXEX) as the dependent variable. For independent variables, we began by including race and sibling sex as control variables (producing $R^{2}=.08$ ). Then, the "package" of sexual behavior measures including sibling SEXEX, best same sex friend SEXEX, and best opposite sex friend SEXEX were added, producing an $R^{2}=.26$ for predicting sexual experience. Next, the "package" of mild deviance measures (sibling DEV, same-sex friend DEV, and opposite-sex friend DEV) were added in a stepwise regression routine that selected the subset of those that signifi- 
TABLE 5

$R^{2}$ s for Predicting Respondent's Sexuality (S) and Deviance (D)

from the IV "Packages": Control Variables (CV), Relevant

Others' Sexuality (OS), Relevant Others' Mild Deviance (OD)

\begin{tabular}{|c|c|c|c|}
\hline \multicolumn{4}{|c|}{ Dependent Variable } \\
\hline \multicolumn{2}{|c|}{ Respondent's Sexuality } & \multicolumn{2}{|c|}{ Respondent's Deviance } \\
\hline $\begin{array}{l}R_{\mathrm{S}, \mathrm{CV}}^{2} \\
R_{2 \mathrm{~S},(\mathrm{CV}, \mathrm{OS})} \\
R_{2}^{2} \mathrm{~S},(\mathrm{CV}, \mathrm{OD}) \\
R_{\mathrm{S},(\mathrm{CV}, \mathrm{OS}, \mathrm{OD})}\end{array}$ & $\begin{array}{l}=.078 \\
=.258 \\
=.126 \\
=.265\end{array}$ & $\begin{array}{l}R^{2} \mathrm{D}, \mathrm{CV} \\
R^{2} \mathrm{D},(\mathrm{CV}, \mathrm{OS}) \\
R_{2}^{2} \mathrm{D},(\mathrm{CV}, \mathrm{OD}) \\
R_{\mathrm{D},(\mathrm{CV}, \mathrm{OS}, \mathrm{OD})}\end{array}$ & $\begin{array}{l}=.214 \\
=.243 \\
=.265 \\
=.275\end{array}$ \\
\hline
\end{tabular}

cantly increased the predictability of the IVs (PROC STEPWISE in SAS was used for this purpose). None of the deviant behavior variables added significantly to predicting sexual behavior (at SAS's default entry level of $\alpha=.15)$. Next, the two "packages" were reversed: The deviant behavior package was added to the control variables, resulting in an $R^{2}=.13$. In the stepwise regression (again, with $\alpha=.15$ ) that added the sexual behavior variables to the deviant behavior package, same-sex friend sexuality added to the predictability $\left(R^{2}=.21\right)$ and sibling sexuality added to the predictability $\left(R^{2}=.26\right)$. The results of predicting respondent's sexuality are summarized as follows:

1. Both sexual experience and deviance of relevant others significantly predicts respondent's sexual experience.

2. Respondent's sexual experience is predicted better by significant others' sexual experience than by significant others' deviance.

3. Significant others' sexual experience contains the component of deviance predictability within it.

4. Significant others' deviance contains only a part of the component of sexual experience predictability within it.

5. Same-sex friend's sexual experience and sibling's sexual experience are the dominant contributors to the prediction of respondent's sexual experience.

Next, the same set of procedures were run to predict a respondent's deviance scores. The two control variables - race and sibling sex - had an $R^{2}=.21$ for predicting mild deviance. When the "package" of deviance measures from siblings, same-sex friend, and opposite-sex friend were entered, $R^{2}=.26$. When PROC STEPWISE tested each of the sexual experience variables for entry into the model, none were significant (at $\alpha=.15$ ). As before, this procedure was reversed, and the "package" of 
sexual experience measures was entered with the control variables, resulting in an $R^{2}=.24$. The stepwise regression procedure then tested the deviance measures for entry into the model (at $\alpha=.15$ ); Sibling deviance contributed significantly, increasing the predictability to $R^{2}=.26$, followed by the entry of same-sex friend deviance into the model with $R^{2}=$ .27. These results are parallel to those obtained for predicting sexual experience:

1. Both sexual experience and deviance of relevant others significantly predicts respondent's mildly deviant behavior.

2. Respondent's deviance is predicted better by significant others' deviance than by significant others' experience.

3. Deviance of significant others contains the component of predictability of sexual experience within it.

4. Sexual experience of significant others contains only part of the deviance predictability of significant others within it.

5. Sibling's deviance and same-sex friend's deviance are the dominant contributors to predicting respondent's deviance.

\section{DISCUSSION}

The predictions derived by considering the adolescent sexuality literature in the context of our integrative framework were largely supported. If we consider that different individuals within an adolescent's environment are impinging on the development of that adolescent, we expect behavior from those with whom an adolescent "shares the most environment" to have the highest predictive relationships to the adolescent. The results support this expectation. The behavior of siblings and of best friends contains separate and significant predictability, and is more predictive than that of other friends. Furthermore, same-sex siblings and same-sex friends are generally more alike than opposite-sex siblings and friends, especially on sexual experience. These patterns suggest that elements of the family and friendship environment act to create behavioral similarity. As discussed before, these data are mute with respect to the factors within the environment that cause these relationships. Both genetic and environmental factors are probably acting for the siblings, and only environmental factors for the friends. The results in Rodgers and Rowe (1988) suggest a specific "older sibling influence effect," identifying one of the "active" elements of the environment that may be affecting adolescent sexual behavior. 
The descriptive results strengthen previous findings from both the ADSEX and other data sets that females are particularly sensitive to the female social environment in which they move. Previously, we knew that they were highly similar to their female best friends on a measure of sexual and deviant behaviors. The current results also demonstrate their similarity to both female siblings and other friends. The female sibling correlations of .61-.71 for deviant behavior are remarkably high for social science settings. Such high degree of sibling similarity suggests a genetic base of influence. However, the difference between the sex composition categories, as well as the significant friendship correlations, suggests more than just hereditary influences.

These patterns were stronger for Whites than for Blacks. Lower levels of similarity between Black siblings and friends - particularly for Black males - is apparent in this data set, as it has been in previous analyses of the ADSEX data and other studies controlling for race. A possible artifactual explanation of this finding is that the sexual experience scale (e.g., Smith \& Udry, 1985) is not a good measure of sexual experience for Blacks. Results were not different enough for the sexual experience count variable to give strong support to this explanation, however. Another methodological consideration is to question whether the correlations are affected by highly skewed distributions. The base rates for both sexual experience and deviant behavior are somewhat different for the four race-sex subgroups (Sexual Behavior, 0 to 11: White males $[\mathrm{WM}]=6.8$, $\mathrm{BM}=9.0, \mathrm{WF}=5.2$, Black Females $[\mathrm{BF}]=5.4$, Deviant Behavior, 0 to $3: \mathrm{WM}=2.3, \mathrm{BM}=1.5, \mathrm{WF}=2.2, \mathrm{BF}=1.4)$. These distributions do not appear skewed enough, however, to invalidate the interpretations of the correlations.

The HMR results provide strong support for the conclusion that there is an overall relationship between sexual behavior and deviance in adolescents. Clearly, the two latent domains overlap; sexual experience is predictable from measures of deviance, and vice versa. But just as clearly, the domains can be separated. Within-domain predictions are stronger than cross-domain predictions. Also, behavior of both sibling and samesex friend add separate components to the predictability, and opposite-sex friends are not as potent predictors. This last fact is especially interesting, because opposite-sex friends are the ones with whom sexual behavior is shared. This finding lends additional support to the importance of social explanations of sexual behavior and deviance.

Several researchers have built theories around the degree of overlap between problem behaviors. In Jessor and Jessor's (1977) Problem Be- 
havior Theory, this tendency to overlap is called a "syndrome." The whole package of such behaviors are called "transition behaviors" by Ensminger (1987), who reviewed this and a number of other theoretical perspectives that can help explain the overlap. Rowe, Rodgers, Meseck-Bushey, and St. John (1989b) called the underlying deviance trait "d." But the tendency for problem behaviors to covary is only half of the picture.

In this article, we have shown that the sexuality and mild deviance domains overlap, but they also can be distinguished empirically. Elliott and Morse (1989, p. 56) found a "typical temporal sequence of delinquency followed by drug use then by sexual intercourse" that can help to explain this finding. If adolescents do tend to enter into these behaviors sequentially, then obviously measures during the entry process will not reflect the complete level of covariance that will ultimately be observed on responses to questions of "Have you ever engaged in ..." a particular behavior. Mott and Haurin (1988) found results similar to ours in a national data set, and concluded that "generalizable links" between transition behaviors could be found for Whites, but for Blacks "substance use and sexual activity are clearly much more discrete events" (p.135).

We conclude by drawing an analogy to another well-known partitioning of variability, the "nature-nurture" issue. There are camps of "environmentalists" and "geneticists," but careful scholars do not ask which, of environment or heredity, is the single cause of behavior, but rather how important each is in accounting for behavioral variability. Similarly, it makes an attractive model to emphasize overlap between transition behaviors. But careful scholars should recognize the importance of both the common and unique contributions to predicting sexuality and deviance.

\section{REFERENCES}

Alan Guttmacher Institute. (1981). Teenage pregnancy: The problem that hasn't gone away. New York: Author.

Antonovsky, H. F., Shoham, I., Kavenaki, S., Lancet, M., \& Modan, B. (1980). Gender differences in patterns of adolescent sexual behavior. Journal of Youth and Adolescence, $9,127-141$.

Billy, J.O.G., Rodgers, J. L., \& Udry, J. R. (1984). Adolescent sexual behavior and friendship choice. Social Forces, 62, 653-678.

Billy, J.O.G., \& Udry, J. R. (1985). The influence of male and female best friends on adolescent sexual behavior. Adolescence, 20, 21-32.

Carroll, J. L., Volk, K. D., \& Hyde, J. S. (1985). Differences between males and females in motives for engaging in sexual intercourse. Archives of Sexual Behavior, 14, 131-139.

Cicirelli, V. G. (1976). Mother-child and sibling-sibling interactions on a problem-solving task. Child Development, 47, 588-596. 
Clayton, R. R. (1972). Premarital sexual intercourse: A substantive test of the contingent consistency model. Journal of Marriage and the Family, 34, 273-281.

Clayton, R. R., \& Bokemeier, J. L. (1980). Premarital sex in the seventies. Journal of Marriage and the Family, 42, 759-775.

Cohen, J., \& Cohen, P. (1975). Applied multiple regression/correlation analysis for the behavior sciences. Hillsdale, NJ: Lawrence Erlbaum.

Donovan, J. E., \& Jessor, R. (1985). Structure of problem behavior in adolescence and young adulthood. Journal of Consulting and Clinical Psychology, 53, 890-904.

Elliott, D. S., \& Morse, B. J. (1989). Delinquency and drug use as risk factors in teenage sexual activity. Youth \& Society, 21, 32-60.

Ensminger, M. E. (1987). Adolescent sexual behavior as it relates to other transition behaviors in youth. In S. Hofferth \& C. Hayes (Eds.), Risking the future: Adolescent sexuality, pregnancy, and childbearing: Working papers and statistical appendices (pp. 36-55). Washington, DC: National Academy Press.

Furstenberg, F. F., Morgan, S. P., Moore, K. A., \& Peterson, J. L. (1987). Race differences in the timing of adolescent intercourse. American Sociological Review, 52, 511-518.

Hayes, C. D. (Ed.). (1987). Risking the future: Adolescent sexuality, pregnancy, and childbearing (Vol. 1). Washington, DC: National Academy Press.

Hofferth, S. L. (1987). Factors affecting initiation of sexual intercourse. In S. Hofferth \& C. Hayes (Eds.), Risking the future: Adolescent sexuality, pregnancy, and childbearing: Working papers and statistical appendices (pp. 7-35). Washington, DC: National Academy Press.

Hofferth, S. L., Kahn, J. R., \& Baldwin, W. (1987). Premarital sexual activity among U.S. teenage women over the past three decades. Family Planning Perspectives, 19, 46-53.

Jessor, R., \& Jessor, S. L. (1977). Problem behavior and psychosocial development. New York: Academic Press.

Koch, H. L. (1957). The relation in young children between characteristics of their playmates and certain attributes of their siblings. Child Development, 28, 175-201.

McCormick, N. B. (1979). Come-ons and put-offs: Unmarried students' strategies for having and avoiding sexual intercourse. Psychology of Women Quarterly, 4, 194-211.

Mirande, A. (1968). Reference group theory in adolescent sexual behavior. Journal of Marriage and the Family, 30, 572-577.

Mott, F. L., \& Haurin, R. J. (1988). Linkages between sexual activity and alcohol and drug use among American adolescents. Family Planning Perspectives, 20, 128-136.

Murstein, B. I., \& Holden, C. C. (1979). Sexual behavior and correlates among college students. Adolescence, 14, 625-639.

Newcomb, M., Huba, G. J., \& Bentler, P. M. (1986). Determinates of sexual and dating behavior among adolescents. Journal of Personality and Social Psychology, 50, 428-438.

Newcomer, S., \& Udry, J. R. (1987). Parental marital status effects on adolescent sexual behavior. Journal of Marriage and the Family, 49, 235-240.

Osgood, D. W., Johnston, L. D., O'Malley, P. M., \& Bachman, J. G. 1988. The generality of deviance in late adolescence and early adulthood. American Sociological Review, 53, 81-93.

Peplau, L. A., Rubin, Z., \& Hill, C. T. (1977). Sexual intimacy in dating relationships. Journal of Social Issues, 33, 86-109.

Reiss, I. L. (1967). The social context of premarital sexual permissiveness. New York: Holt, Rinehart \& Winston.

Reiss, I. L. (1970). Premarital sex as deviant behavior: An application of current approaches to deviance. American Sociological Review, 35, 78-87. 
Rodgers, J. L. (1983). Family configuration and adolescent sexual behavior. Population and Environment, 6, 78-87.

Rodgers, J. L., Billy, J.O.G., \& Udry, J. R. (1982). The rescission of behaviors: Inconsistent responses in adolescent sexuality data. Social Science Research, 11, 280-296.

Rodgers, J. L., Billy, J.O.G., \& Udry, J. R. (1984). A model of friendship similarity in mildly deviant behaviors. Journal of Applied Social Psychology, 14, 413-425.

Rodgers, J. L., \& Rowe, D. C. (1988). Influence of siblings on adolescent sexual behavior. Developmental Psychology, 24, 722-728.

Rowe, D. C., Rodgers, J. L., \& Meseck-Bushey, S. (1989). An "epidemic" model of sexual intercourse prevalences for Black and White adolescents. Social Biology, 36, 127-145.

Rowe, D. C., Rodgers, J. L., Meseck-Bushey, S., \& St. John, C. (1989). Sexual behavior and deviance: A sibling study of their relationship. Developmental Psychology, 25, 61-69.

Shah, F. K., \& Zelnick, M. L. (1981). Parent and peer influences on sexual behavior, contraceptive use, and pregnancy experience of young women. Journal of Marriage and the Family, 43, 339-348.

Smith, E. A., \& Udry, J. R. (1985). Coital and non-coital sexual behaviors of white and black adolescents. American Journal of Public Health, 75, 1200-1203.

Spanier, G. B. (1976). Perceived sex knowledge, exposure to eroticism, and premarital sexual behavior: The impact of dating. Sociological Quarterly, 17, 247-261.

Stern, M., Northman, J. E., \& Van Slyck, M. R. (1984). Father absence and adolescent problem behaviors: Alcohol consumption, drug use and sexual activity. Adolescence, 19, 301-312.

Strobino, D. M. (1987). The health and medical consequences of adolescent sexuality and pregnancy: A review of the literature. In S. Hofferth \& C. Hayes (Eds.), Risking the future: Adolescent sexuality, pregnancy, and childbearing: Working papers and statistical appendices (pp. 93-122). Washington, DC: National Academy Press.

Teevan, J. J. (1972). Reference groups and premarital sexual behavior. Journal of Marriage and the Family, 34, 283-291.

Thornton, A., \& Camburn, D. (1987). The influence of the family on premarital sexual attitudes and behavior. Demography, 24, 323-340.

Udry, J. R., Billy, J.O.G., Morris, N., Groff, T., \& Raj, M. (1985). Serum androgenic hormones motivate sexual behavior in adolescent boys. Fertility and Sterility, 43, 90-94.

Udry, J. R., Talbert, L. M., \& Morris, N. M. (1986). Biosocial foundations for adolescent female sexuality. Demography, 23, 217-230.

Wilcox, S., \& Udry, J. R. (1986). Autism and accuracy in adolescent perceptions of friends' sexual attitudes and behavior. Journal of Applied Social Psychology, 16, 361-374.

Yamaguchi, K., \& Kandel, D. (1987). Drug use and other determinants of premarital pregnancy and its outcome: A dynamic analysis of competing life events. Journal of Marriage and the Family, 49, 257-270.

Zabin, L. S., Hardy, J. B., Smith, E. A., \& Hirsh, M. B. (1986). Substance use and its relation to sexual activity among inner-city adolescents. Journal of Adolescent Health Care, 7, 320-331.

Zelnick, M., \& Kantner, J. F. (1980). Sexual activity, contraceptive use, and pregnancy among metropolitan teenagers: 1971-1979. Family Planning Perspectives, 12, 230-237.

Zelnick, M., Kantner, J. F., \& Ford, K. (1981). Sex and pregnancy in adolescence. Beverly Hills, CA: Sage. 